\title{
Determinants of age at first marriage in Ethiopia using 2016 Ethiopian Demographic and Health Surveys: Application of Cox Proportional Hazard model
}

\author{
Masrie Getnet ( $\square$ masriegetnet16.biostat@gmail.com ) \\ Jimma University https://orcid.org/0000-0001-6984-8147 \\ Chaltu Fikru \\ Jimma University \\ Tamrat Shewano \\ Jimma University
}

Research article

Keywords: Age at first marriage, Cox proportional hazard model, Ethiopia

Posted Date: September 24th, 2019

DOl: https://doi.org/10.21203/rs.2.14902/v1

License: (c) (1) This work is licensed under a Creative Commons Attribution 4.0 International License.

Read Full License 


\section{Abstract}

Background Although, determining age at first marriage has a various socioeconomic and demographic implications, available information in Ethiopia is nearly scanty.

Methods We used data from the 2016 Ethiopian Demographic and Health Survey. The survival information of a total of 15,683 women with reproductive age (15-49) were examined. Cox proportional hazards regression model was employed to identify the determinants of age at first marriage.

Results The highest probability of getting age at first marriage occurred in the early age of women, whereas the probability of getting age at first marriage were lower in the later age of women. In Ethiopia more than $44 \%$ of women were married before turning 18 years. The median age at first marriage was 17 years old. According to multivariate Cox proportional hazard model, significant variables of age at first marriage were; women's educational level with secondary and above ( $\mathrm{HR}=0.9,95 \% \mathrm{Cl}: 0.80-0.92)$, regions; Tigray (HR=1.6, 95\% Cl: 1.43-1.75), Afar ( $\mathrm{HR}=1.6,95 \% \mathrm{Cl}$ : 1.43-1.78), Amhara (HR=1.6, 95\% Cl: 1.46-1.79), Oromia (HR=1.3, 95\% Cl: 1.18-1.45), Somalia (HR=1.4, 95\%Cl: 1.26-1.57), Benishangul (HR=1.4, 95\%Cl: 1.25-1.55), Southern Nations, Nationalities, and Peoples' Region (SNNPR) (HR=1.4, 95\%Cl: 1.29-1.60), Gambela (HR=1.5, 95\%Cl: 1.30-1.62), Harari (HR=1.2, 95\% Cl: 1.10-1.35) \& Driedawa (HR=1.3, 95\% Cl: 1.20-1.47), women's from rural residence ( $\mathrm{HR}=1.1,95 \% \mathrm{Cl}: 1.03-1.18)$, Muslim women's (HR=1.1, 95\% Cl: 1.0-1.20), getting first marriage who had first sex $<15$ years $(\mathrm{HR}=2.6,95 \% \mathrm{Cl}: 2.44-2.69)$ \& getting first marriage who had first sex $\geq 20$ years and household with $\geq 5$ members (HR=1.1, 95\% Cl: 1.01-1.12) compared to their counterparts.

Conclusion Women's educational level with secondary and above, regions out of Addis Ababa, women's from rural area, religion being Muslim, women's who had first sex $<15$ years, women's who had first sex $\geq$ 20 years and household with $\geq 5$ members were the significant determinants of age at first marriage. Women's with lower education, residing out of Addis Ababa and rural Ethiopia, being Muslim, who had first sex $<15$ years old and five \& more members in the household deserve special attention.

\section{Background}

Marriage is a recognized union of spouses; the recognition is may be either legally or socially. Marriage is formalized by a weeding or a small ceremony at the community or family level [1]. It is also an important family organization for the individual and the communities at large. Marriage is unforgettable events in one's life cycle, besides the most important thing for family formation or family foundation process [2].

Individuals may marry for different reasons, including religious purpose, financial, emotional, social or legal purposes. The marriage is not only the individual desires it might be influenced by the family choices, perspective marriage rules, societal influences or influenced by genders. In some parts of the world, forced marriage and early marriage practiced as a culture or tradition, on the other hand, such practice is penalized by law out of the women's right, or children (both male and female) rights because of the international law [3]. 
Child marriage is a type of marriage below the age of 18 years. The marriage is carried out before the children are physically, financially, physiologically and psychologically ready to shoulder the responsibilities of marriage, the way how to manage the families and childbearing [4].Children lost a lot of things, including educational opportunities, leads to poverty, negative impact on health and decision making capacities [5].

The proportion of girls marrying as children is declining at the global level, and there has also been progress in Ethiopia in recent decades. But, still marry before turning 18 is a problem [6,7]. Therefore, the aims of this study was to examine the effect of sociodemographic factor on age at first marriage among reproductive women in Ethiopia.

\section{Methods}

\section{Study design and setting}

The dataset used in this study was obtained from MEASURE DHS database at http://dhsprogram.com/data/ for Ethiopian Demographic and Health Survey conducted in 2016, which is the fourth comprehensive survey. It was a population-based cross-sectional study conducted across the country.Administratively, Ethiopia is divided into nine geographical regions (Tigray, Afar, Amhara, Oromia, Somali, Benishangul-Gumuz, SNNPR, Gambella and Harari) and two administrative cities Addis Ababa and Dire dawa.

\section{Sampling procedures}

The 2016 EDHS sample was stratified and selected in two stages. Each region was stratified into urban and rural areas, yielding 21 sampling strata. Samples of Enumeration Areas (EAs) were selected independently in each stratum in two stages. Implicit stratification and proportional allocation were achieved at each of the lower administrative levels by sorting the sampling frame within each sampling stratum before sample selection, according to administrative units in different levels, and by using a probability proportional to size selection at the first stage of sampling.

In the first stage, a total of 645 EAs (202 in urban areas and 443 in rural areas) were selected with probability proportional to EA size based on the 2007 population housing census and with independent selection in each sampling stratum. A household listing operation was carried out in all of the selected EAs from September to December 2015. The resulting lists of households served as a sampling frame for the selection of households in the second stage. Some of the selected EAs were large, consisting of more than 300 households. To minimize the task of household listing, each large EA selected for the 2016 EDHS was segmented. Only one segment was selected for the survey with probability proportional to segment size. Household listing was conducted only in the selected segment; that is, a 2016 EDHS cluster is either an EA or a segment of an EA. 
In the second stage of selection, a fixed number of 28 households per cluster were selected with an equal probability systematic selection from the newly created household listing. All women age 15-49 who were either permanent residents of the selected households or visitors who stayed in the household the night before the survey were eligible to be interviewed.

A representative sample of 18008 households were selected for the 2016 EDHS. In the interviewed households, 16,583 eligible women were identified for individual interviews. Interviews were completed with 15,683 women, yielding a response rate of $95 \%$ [4].

\section{Study Variables}

The dependent variable was age at first marriage measured in complete years, while the independent variables were educational level of women's, region, place of residence, household has radio, household who had television, religion, wealth index, age at first sexual intercourse, occupational status and family members in the household.

\section{Statistical Analysis}

Both descriptive and Cox regression model were applied for statistical analysis of age at first marriage using Statistical Package for Social Science (SPSS) version 23 software. Variables with a p-value of $<0.25$ at the univariate Cox regression analysis were included into multivariable Cox regression model in which hazard ratio with $95 \%$ confidence intervals were estimated to identify the determinants of age at first marriage. Besides, P-values $<0.05$ were employed to declare the statistical significance.

\section{Results}

\section{Background characteristics of women}

Table 1 shows the distribution of women by selected socio-demographic predictors of age at first marriage in Ethiopia. In this study, a total of 15,683 women were included. From the total women, $11405(72.7 \%)$ and $4278(27.3 \%)$ were married and unmarried respectively. The majority, $6137(39.1 \%)$ of women were married between 15-19 years, 2701(17.2\%) women were married too early (under 15 years) and $2567(16.4 \%)$ women were married above 20 years. About 7033(44.8\%), 5213(33.2\%) and $3437(21.9 \%)$ women had illiterate, primary and above secondary education respectively. The distribution of women by region were 1682(10.7\%) in Tigray, 1128(7.2\%) in Afara, 1719(11.0\%) in Amhara, 1892(12.1\%) in Oromia, 1391(8.9\%) in Somalia, 1126(7.2\%) in Benishangul, 1849(11.8\%) in Southern Nations, Nationalities, and Peoples' Region (SNNPR), 1035(6.6\%) in Gambela, 906(5.8\%) in Harari, $1131(7.2 \%)$ in Dire dawa and 1824(11.6\%) in Addis Ababa. Nearly 5348(34.1\%) and 10335(65.9\%) women were lived in urban and rural parts of Ethiopia respectively. Of the total 5123(32.7\%) \& $4223(26.9 \%)$ household had radio and television respectively. Distribution by religion shows that 
6413(40.9\%), 91(0.6\%), 2814(17.9\%), 6209(39.6\%), and 156(1.0\%) women were Orthodox, Catholic, Protestant, Muslim and other respectively. The majority, 5940(37.9) \% and 7741(49.4\%) of the women were in the poor and rich wealth index groups respectively. Only 2002(12.8\%) of the women were in the middle wealth index group. Table 1 also showed that 7591(48.4\%) of women had their first sex below 18 years; $4371(27.9 \%)$ of women had their first sex at 18 years and above, and only $3721(23.7 \%)$ of the women had not initiated sexual activity. From the total women, 7638(48.7\%) of them had work, while $8045(51.3 \%)$ of them had not work. In this study $6029(38.4 \%)$ of the household had $<5$ family members and $9654(61.6 \%)$ of the household had $\geq 5$ family members. Median age at first marriage was two years older among urban women than rural women, it varies by region from 15 years among women in Amhara to 20 years among women in Addis Ababa The median age at first marriage increases with increasing education, from 16 years among women with no education to 19 years among women with more than a secondary education. A one year older increases of age at first marriage was observed among women with rich wealth index group than women with poor wealth index group.

\section{Kaplan-Meier estimates for overall all age at first marriage in Ethiopia}

The overall estimates of the Kaplan-Meier survivor function showed that, the highest probability of getting age at first marriage were occurred in the early age, whereas the survival function was declined when the age of women increases, suggested that, the probability of getting marriage were lower in the later age of women (Figure 1).

\section{Cox Proportional Hazards Regression Model Results}

Univariate analyses were done to assess the association between all important predictors and age at first marriage. The overall categorical variables with a p-value of $<0.25$ at the univariate analysis were included into multivariable Cox proportional hazard model in which hazard ratio with $95 \%$ confidence intervals were estimated to identify the predictors of age at first marriage. P-values less than 0.05 were employed to declare the statistical significance. These are detailed below (table 2).

The estimated hazard ratio for women with above secondary education was $0.9(95 \% \mathrm{Cl}: 0.80-0.92)$, compared to non-educated (reference category). It was found that the risk of getting first marriage was 0.9 times lower than women with non-educated.

Compared to Addis Ababa (the reference category), the estimated hazard ratios for regions; Tigray, Afar, Amhara, Oromia, Somali, Benishangul, Southern Nations, Nationalities, and Peoples' Region (SNNPR), Gambela, Harari and Drie dawa were 1.6(95\% Cl: 1.43-1.75), 1.6(95\% Cl: 1.43-1.78), 1.6(95\% Cl: 1.461.79), 1.3(95\% Cl: 1.18-1.45), 1.4(95\% Cl: 1.26-1.57), 1.4(95\% Cl: 1.25-1.55), 1.4(95\% Cl: 1.29-1.60), 1.5(95\% Cl: $1.30-1.62), 1.2(95 \% \mathrm{Cl}: 1.10-1.35)$ and $1.3(95 \% \mathrm{Cl}: 1.20-1.47)$ respectively. It showed that the risk of getting early marriage in all regions were higher compared with Addis Ababa. 
The hazard of getting first marriage was 1.1 times higher in rural women's than women who lived in urban, since the estimated hazard ratio for women who lived in rural area was $1.1(95 \% \mathrm{Cl}$ : 1.03-1.18), compared to women who lived in urban (reference category).

The estimated hazard ratio for Muslim women was 1.1(95\% Cl:1.0-1.2), compared to Orthodox (the reference category). It was found that the hazard of early marriage was more pronounced among Muslim than Orthodox or the risk of getting first marriage for Muslim was 1.1 times higher than Orthodox.

It was found that the risk of getting first marriage for women who had first sex less than 15 years old was 2.6 times higher than women had first sex in between 15 to 19 years old, whereas the risk of getting first marriage for women who had first sex above 20 years old was 0.36 times lower than women who had first sex in between 15 to 19 years old, since the estimated hazard ratio for women who had first sex less than 15 years old and women who had first sex above 20 years old were $2.6(95 \% \mathrm{Cl}$ : $2.44-2.69)$ and $0.36(95 \% \mathrm{Cl}: 0.35-0.39)$, compared to women who had first sex in between 15 to 19 years old (the reference category) respectively.

The risk of getting early marriage was 1.1 times higher in households with five and more family members than households with less than five family members, since the estimated hazard ratio for five and more household family members was $1.1(95 \% \mathrm{Cl}: 1.01-1.12)$, compared to less than five household family members.

\section{Discussion}

The main aim of this study was to identify the determinant of infant mortality in Ethiopia, using 2016 EDHS. The analyses revealed that the educational level of women, region, place of residence, religion, age at first sexual intercourse, and family members in the household had statistical significant to age at first marriage. The study also found that the median age at first marriage in Ethiopia was 17 years old.

The finding of this study found that the risk of getting early marriage was lower among women with secondary and above educational level than women with non-educated. The result of this findings could be the educated women can identify the consequences of early marriage. They would have the plan to learn, to strength economically, socially and they make strong them in different aspects before marriage. A study (8) conducted in Nigeria suggested that the higher the level of education of the women, the lower the hazard of early marriage. A study (9) conducted in Bangladesh found that the higher education of the respondents is likely to be associated with lower probability of early marriage. A study (10) conducted in Kenya also found that the education had a statistically significant effect on the timing of marriage; more educated women were less likely to marry early.

The finding of this study revealed that early marriage was higher in all regions of Ethiopia than Addis Ababa. Provinces may have different levels of socioeconomic development and may be culturally different, which may lead to differences in age at first marriage. Besides, the tradition, awareness about the side effect of early marriage, poor implementation of policies and programs, less civilization of the 
people, infrastructure and others, all these cumulative effects would leads the highest early marriage in the regions of Ethiopia out of Addis Ababa. A study (12) conducted in Mozambique found that ethnicity is an important predictor of age at first marriage.

The finding of this study revealed that getting age at first marriage was higher among women who reside in rural than urban area. Rural areas tend to have institutional and normative structures such as the kinship and extended family that promote early marriage and childbearing. A study (8) conducted in Nigeria found that women who are lived in rural area had a higher risk of first marriage than urban area i.e., hazard of women living in rural is greater than urban. A study (9) conducted in Bangladesh found that the age at first marriage of the study rural women was little higher. A study (11) in Kenya suggested that, delayed age at first sexual debut among women in urban areas significantly reduces the risk of entering into first marriage.

This study found that Muslim women were more pronounced for early marriage than Orthodox. The guidance of getting age at first marriage might be different based on their thoughts among different religions. A study (8) conducted in Nigeria supported that the hazard of early marriage was higher among Muslim women than Christians.

The study of this finding revealed that the risk of getting first marriage for women who had first sex with less than 15 years old was higher than who had first sex in between 15 to 19 years old and the risk of getting first marriage for women who had first sex above 20 years old was lower than women who had first sex in between 15 to 19 years old. This could be when women who had first sex under 15 years they would expose to unsafe sex, pregnancy and others. Also, they couldn't have the right to decided when they marry, since they depend with their families. Because of these and other reasons they would have enforced to marry early, whereas women who had first sex above 20 years old, they can to convince when they to marry and they can to challenge early marriage. A study (8) conducted in Kenya showed that age at first sexual intercourse was inversely related to age at first marriage. This means an increase in age at first sexual intercourse would lead to reduction in age at first marriage. A study (11) conducted in Kenya also found that women in urban areas who engaged in first sexual intercourse below ages 15 years were more likely to enter into marriage than those between ages 15-19 years and 20 years.

The study of this finding revealed that the risk of getting early marriage was higher among household with high family members than household with low family members. The result of this study could be when the household be with high family members they would to expose for economic crisis, then this would facilitate early marriage. A study (8) conducted in Nigeria found that the total child ever born was negatively related to age at first marriage.

\section{Conclusions}

The study demonstrated that women's educational level, region, place of residence being rural, religion, age at first sexual intercourse, and family members in the household had statistically significant impact 
on age at first marriage. Also, it demonstrated that the more than $44 \%$ of women married early in Ethiopia. More over the median survival time is 17 years old.

Empowering the education of women, regions out of Addis Ababa, rural women's, religion being Muslim, women's who had first sex with $<15$ years old and five family members \& more in the household needs a better attention and conducting interventional studies on these variables are crucial.

\section{Abbreviations}

EDHS: Ethiopian Demographic and Health Survey, SNNPR: South Nations Nationalities and Peoples of Ethiopia, HR: Hazard Ratio, CSA: Ethiopian Central Statistical Agency

\section{Declarations}

\section{Ethics approval and consent to participate}

The DHS surveys have been reviewed and approved by ICF Institutional Review Board (IRB). Moreover, DHS survey protocols are reviewed by the ICF IRB and an IRB in the host country. The consents is available at https://www.dhsprogram.com/What-We-Do/Protecting-the-Privacy-of-DHS-SurveyRespondents.cfm

\section{Consent for publication}

Not applicable

\section{Availability of data and materials:}

Data is available from MEASURE DHS database at https://dhsprogram.com/data/available-datasets.cfm

\section{Competing interests:}

The authors declare that they have no competing interests

\section{Funding:}

Not applicable

\section{Authors' contributions:}


MG: conceived the study, formulated the research questions, and designed the study, MG: analyzed the data, and drafted the paper. MG, CF and TS: did the analysis, reviewed the paper for intellectual content. All authors read and approved the final manuscript.

\section{Acknowledgments:}

We acknowledge Ethiopian Central Statistical Agency (CSA) for online data permission.

\section{References}

1. Haviland, William A.; Prins, Harald E. L.; McBride, Bunny; Walrath, Dana (2011). Cultural Anthropology: The Human Challenge (13th ed.). Cengage Learning. ISBN 978-0-495-81178-7. "A nonethnocentric definition of marriage is a culturally sanctioned union between two or more people that establishes certain rights and obligations between the people, between them and their children, and between them and their in-laws."

2. Palamuleni, M. 2011. Socioeconomic determinants of age at marriage in Malawi: InternationalJournal of Sociology and Anthropology,3(7): 224-235

3. Country Reports on Human Rights Practices for 2008, Vol. 1, p. 1353, US Department of State.

4. Walker JA, Mukisa S, Hashim Y, Ismail H (2013) Mapping Early Marriage in West Africa: a scan of trends, interventions, what works, best practices and the way forward Lagos: Ford Foundation, West Africa Office

5. EGLDAM, UNIFEM and UNFPA, Early Marriage in Ethiopia: Law and Social Reality,2005

6. Wodon, Q., C. Male, A. Nayihouba, A. Onagoruwa, A. Savadogo, A. Yedan, A. Kes, N. John, M. Steinhaus, L. Murithi, J. Edmeades, and S. Petroni (2018). Economic Impacts of Child Marriage: Ethiopia Country Brief. Washington, DC: The World Bank and International Center for Research on Women.

7. Gurmu, E. and D. Etana, Age at First Marriage and First Birth Interval in Ethiopia: Analysis of the Roles of Social and Demographic Factors. 1332-1344.

8. Adebowale, A., et al., Survival Analysis of Timing of First Marriage among Women of Reproductive age in Nigeria: Regional Differences. 95-107.

9. Aktar S, Mondal S, Hossain A, Rashid H. Socio-economic Determinants of Age at First Marriage of Rural Women: A Statistical Analysis. International Journal Of Engineering And Computer Science ISSN:2319-7242 Volume 6 Issue 12 December 2017, Page No. 22255-22260 Index Copernicus value (2015): 58.10, 76.25 (2016) DOI: 10.18535/ijecs/v6i12.03

10. Lawrence D. E. Ikamari. The effect of education on the timing of marriage in Kenya. DEMOGRAPHIC RESEARCH VOLUME 12, ARTICLE 1, PAGES 1-28 PUBLISHED 23 FEBRUARY 2005 www.demographic-research.org/Volumes/Vol12/1DOI: 10.4054/DemRes.2005.12.1 
11. Adedokun, O. A., 1999. Shifting Patterns of Age at First Marriage and Implications for Family Size in Metropolitan Lagos (Nigeria). Union for African Population Studies. Summary Report number 41, Dakar, p. 16.0

12. Arnaldo, Carlos. (2004). "Ethnicity and Marriage Patterns in Mozambique". African Population Studies vol. 19(1): 143-164.

\section{Tables}

Table 1: Distribution of women by selected socio-demographic predictors of age at first Marriage with its median survival time in Ethiopia. 


\begin{tabular}{|c|c|c|c|c|c|}
\hline \multirow[t]{2}{*}{ Variables } & \multirow[t]{2}{*}{ Categories } & \multicolumn{2}{|c|}{ Status } & \multirow[t]{2}{*}{ Total } & \multirow{2}{*}{$\begin{array}{c}\text { Median } \\
\text { Survival } \\
\text { time }\end{array}$} \\
\hline & & Married & Unmarried & & \\
\hline \multirow{3}{*}{$\begin{array}{l}\text { Educational level } \\
\text { of women }\end{array}$} & No education & $6506(41.5 \%)$ & $527(3.4 \%)$ & 7033(44.8\%) & 16 \\
\hline & Primary & $3209(20.5 \%$ & $2004(12.8 \%)$ & $5213(33.2 \%)$ & 17 \\
\hline & $\begin{array}{l}\text { Secondary \& } \\
\text { above }\end{array}$ & $1690(10.8 \%)$ & $1747(11.1 \%)$ & $3437(21.9 \%)$ & 19 \\
\hline \multirow{11}{*}{ Region } & Tigray & $1239(7.9 \%)$ & $443(2.8 \%)$ & 1682(10.7\%) & 16 \\
\hline & Afar & $962(6.1 \%)$ & $166(1.1 \%)$ & $1128(7.2 \%)$ & 16 \\
\hline & Amhara & $1347(8.6 \%)$ & $372(2.4 \%)$ & $1719(11.0 \%)$ & 15 \\
\hline & Oromia & $1462(9.3 \%)$ & $430(2.7 \%)$ & 1892(12.1\%) & 16 \\
\hline & Somali & $1089(6.9 \%)$ & $302(1.9 \%)$ & $1391(8.9 \%)$ & 17 \\
\hline & Benishangul & $886(5.6 \%)$ & $240(1.5 \%)$ & $1126(7.2 \%)$ & 16 \\
\hline & SNNPR & 1293(8.2\%) & $556(3.5 \%)$ & $1849(11.8 \%)$ & 17 \\
\hline & Gambela & $829(5.3 \%)$ & $206(1.3 \%)$ & $1035(6.6 \%)$ & 16 \\
\hline & Harari & $679(4.3 \%)$ & $227(1.4 \%)$ & $906(5.8 \%)$ & 17 \\
\hline & Drie dawa & $752(4.8 \%)$ & $379(2.4 \%)$ & $1131(7.2 \%)$ & 17 \\
\hline & Addis Ababa & $867(5.5 \%)$ & $957(6.1 \%)$ & $1824(11.6 \%)$ & 20 \\
\hline \multirow[t]{2}{*}{ Place of residence } & Urban & 3183(20.3\%) & $2165(13.8 \%)$ & $5348(34.1 \%)$ & 18 \\
\hline & Rural & $8222(52.4 \%)$ & $2113(13.5 \%)$ & $10335(65.9 \%)$ & 16 \\
\hline \multirow{2}{*}{$\begin{array}{l}\text { Household has } \\
\text { radio }\end{array}$} & Yes & $3430(21.9 \%)$ & 1693(10.8\%) & $5123(32.7 \%)$ & 16 \\
\hline & No & 7975(50.9\%) & $2585(16.5 \%)$ & $10560(67.3 \%)$ & 17 \\
\hline \multirow{2}{*}{$\begin{array}{l}\text { Household has } \\
\text { television }\end{array}$} & Yes & $2458(15.7 \%)$ & 1765(11.3\%) & $4223(26.9 \%)$ & 16 \\
\hline & No & $8947(57.0 \%)$ & $2513(16.0 \%)$ & $11460(73.1 \%)$ & 18 \\
\hline \multirow{5}{*}{ Religion } & Orthodox & $4366(27.8 \%)$ & $2047(13.1 \%)$ & $6413(40.9 \%)$ & 17 \\
\hline & Catholic & $66(0.4 \%)$ & $25(0.2 \%)$ & $91(0.6 \%)$ & 17 \\
\hline & Protestant & 1991(12.7\%) & $823(5.2 \%)$ & $2814(17.9 \%)$ & 17 \\
\hline & Muslim & $4845(30.9 \%)$ & 1364(8.7\%) & $6209(39.6 \%)$ & 16 \\
\hline & Other & $137(0.9 \%)$ & $19(0.1 \%)$ & $156(1.0 \%)$ & 17 \\
\hline
\end{tabular}




\begin{tabular}{|l|l|l|l|l|c|}
\multirow{4}{*}{ Wealth index } & Poor & $4959(31.6 \%)$ & $981(6.3 \%)$ & $5940(37.9 \%)$ & 16 \\
\cline { 2 - 6 } & Middle & $15329(9.8 \%)$ & $470(3.0 \%)$ & $2002(12.8 \%)$ & 16 \\
\cline { 2 - 6 } & Rich & $4914(31.3 \%)$ & $2827(18.0 \%)$ & $7741(49.4 \%)$ & 17 \\
\hline \multirow{2}{*}{$\begin{array}{l}\text { Occupational } \\
\text { status of women }\end{array}$} & Had work & $5611(35.8 \%)$ & $2027(12.9 \%)$ & $7638(48.7 \%)$ & 16 \\
\cline { 2 - 6 } & Not had & $5794(36.9 \%)$ & $2251(14.4 \%)$ & $8045(51.3 \%)$ & 17 \\
\hline \multirow{2}{*}{$\begin{array}{l}\text { Household } \\
\text { members }\end{array}$} & $<5$ & $4561(29.1 \%)$ & $1468(9.4 \%)$ & $6029(38.4 \%)$ & 17 \\
\cline { 2 - 6 } & $\geq 5$ & $6844(43.6 \%)$ & $2810(17.9 \%)$ & $9654(61.6 \%)$ & 16 \\
\hline
\end{tabular}

Table 2: Cox's Proportional Hazards Regression Results of age at first marriage in Ethiopia. 


\begin{tabular}{|c|c|c|c|c|}
\hline Variables & Categories & $\begin{array}{l}\text { Estimated } \\
\text { HRs }\end{array}$ & \multirow[t]{2}{*}{$\begin{array}{c}\text { 95\% CI for } \\
\text { HRs }\end{array}$} & \multirow[t]{2}{*}{$\begin{array}{l}\mathrm{P}- \\
\text { values }\end{array}$} \\
\hline \multirow{3}{*}{$\begin{array}{l}\text { Educational level of } \\
\text { women }\end{array}$} & No education (ref) & 1 & & \\
\hline & Primary & 1.0 & $\begin{array}{l}(0.99 \\
1.09)\end{array}$ & 0.089 \\
\hline & Secondary and above & 0.9 & $\begin{array}{l}(0.80 \\
0.92)\end{array}$ & 0.000 \\
\hline \multirow{11}{*}{ Region } & Tigray & 1.6 & $\begin{array}{l}(1.43, \\
1.75)\end{array}$ & 0.000 \\
\hline & Afar & 1.6 & $\begin{array}{l}(1.43, \\
1.78)\end{array}$ & 0.000 \\
\hline & Amhara & 1.6 & $\begin{array}{l}(1.46, \\
1.79)\end{array}$ & 0.000 \\
\hline & Oromia & 1.3 & $\begin{array}{l}(1.18, \\
1.45)\end{array}$ & 0.000 \\
\hline & Somali & 1.4 & $\begin{array}{l}(1.26, \\
1.57)\end{array}$ & 0.000 \\
\hline & Benishangul & 1.4 & $\begin{array}{l}(1.25, \\
1.55)\end{array}$ & 0.000 \\
\hline & SNNPR & 1.4 & $\begin{array}{l}(1.29, \\
1.60)\end{array}$ & 0.000 \\
\hline & Gambela & 1.5 & $\begin{array}{l}(1.30, \\
1.62)\end{array}$ & 0.000 \\
\hline & Harari & 1.2 & $\begin{array}{l}(1.10, \\
1.35)\end{array}$ & 0.001 \\
\hline & Drie Dawa & 1.3 & $\begin{array}{l}(1.20, \\
1.47)\end{array}$ & 0.000 \\
\hline & Addis Ababa ${ }^{(r e f)}$ & 1 & & \\
\hline Place of residence & $\operatorname{Urban}^{(\mathrm{ref})}$ & 1 & & \\
\hline
\end{tabular}




\begin{tabular}{|c|c|c|c|c|}
\hline & Rural & 1.1 & $\begin{array}{l}(1.03, \\
1.18)\end{array}$ & 0.008 \\
\hline \multirow[t]{2}{*}{ Household has radio } & Yes $^{(\text {ref })}$ & 1 & & \\
\hline & No & 1.0 & $\begin{array}{l}(0.95 \\
1.04)\end{array}$ & 0.853 \\
\hline \multirow{2}{*}{$\begin{array}{l}\text { Household has } \\
\text { television }\end{array}$} & Yes $^{\text {(ref) }}$ & & & \\
\hline & No & 0.98 & $\begin{array}{l}(0.91, \\
1.06)\end{array}$ & 0.606 \\
\hline \multirow{5}{*}{ Religion } & Orthodox $^{(\text {ref })}$ & 1 & & \\
\hline & Catholic & 1.1 & $\begin{array}{l}(0.86 \\
1.41)\end{array}$ & 0.449 \\
\hline & Protestant & 1.1 & $(1.0,1.15)$ & $\begin{array}{c}0 \\
.049\end{array}$ \\
\hline & Muslim & 1.1 & $\begin{array}{l}(1.03, \\
1.15)\end{array}$ & 0.005 \\
\hline & Other & 1.1 & $\begin{array}{l}(1.00, \\
1.28)\end{array}$ & 0.441 \\
\hline \multirow[t]{3}{*}{ Wealth index } & Poor & 1.0 & $\begin{array}{l}(0.95, \\
1.07)\end{array}$ & .0767 \\
\hline & Middle $^{(\mathrm{ref})}$ & 1 & & \\
\hline & Rich & 1.0 & $\begin{array}{l}(0.91, \\
1.04)\end{array}$ & 0.449 \\
\hline \multirow{3}{*}{$\begin{array}{l}\text { Age at first sexual } \\
\text { intercourse }\end{array}$} & Had sex less than 15 years old & 2.6 & $\begin{array}{l}(2.44, \\
2.69)\end{array}$ & 0.000 \\
\hline & $\begin{array}{l}\text { Had sex in between } 15 \text { to } 19 \\
\text { years old }^{\text {(ref) }}\end{array}$ & 1 & & \\
\hline & had sex above 20 years old & 0.4 & $\begin{array}{l}(0.35, \\
0.39)\end{array}$ & 0.000 \\
\hline Occupational status & & 1 & & \\
\hline
\end{tabular}




\begin{tabular}{|l|l|c|c|c|}
\multirow{3}{*}{ of women } & Had work $^{(\mathrm{ref})}$ & & & \\
\cline { 2 - 5 } & Not had work & 1.0 & $\begin{array}{c}(0.96, \\
1.04)\end{array}$ & 0.935 \\
\hline House hold members & $<5$ & 1 & & \\
\cline { 2 - 5 } & $\geq 5$ & 1.1 & $\begin{array}{r}(1.01, \\
1.12)\end{array}$ & $\mathbf{0 . 0 0 6}$ \\
\hline
\end{tabular}

$(\mathrm{ref})=$ reference category

\section{Figures}

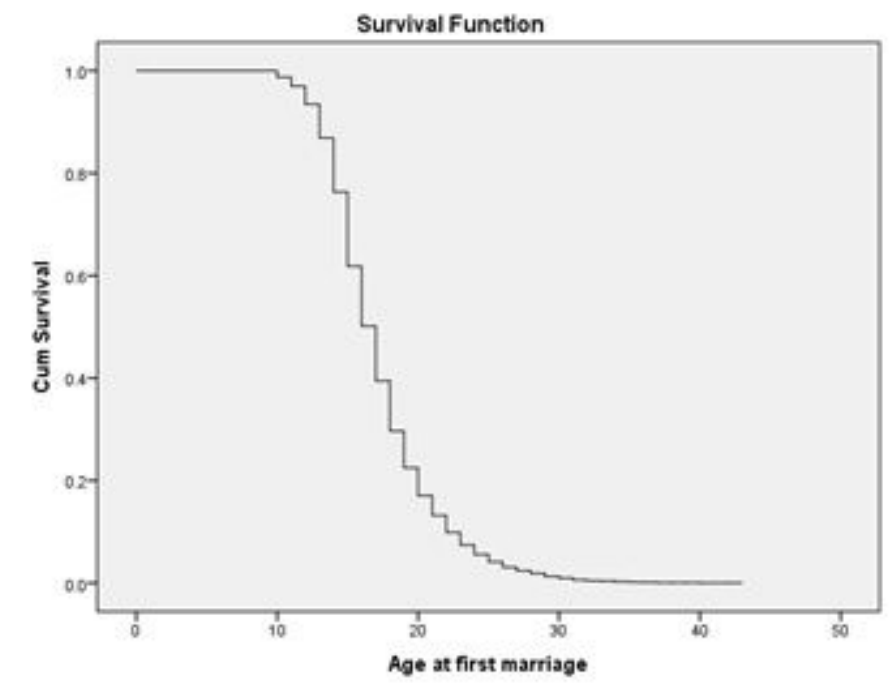

Figure 1

Kaplan-Meier estimates for overall time-to-age at first marriage 